\title{
Time-resolved photoluminescence for evaluating laser-induced damage during dielectric stack ablation in silicon solar cells
}

Stéphanie Parola, Danièle Blanc-Pélissier, Corina Barbos, Marine Le Coz, Gilles Poulain*, Mustapha Lemiti.

Université de Lyon; Institut des Nanotechnologies de Lyon INL-UMR5270, CNRS ; INSA Lyon ; Villeurbanne, F-69621, France.

*TOTAL MS - New Energies, R\&D Division, La Défense, France

Corresponding author:

D. Blanc-Pélissier

Université de Lyon, Institut des Nanotechnologies de Lyon INL, INSA Lyon, Villeurbanne, F-69621.

daniele.blanc@insa-lyon.fr

Tel: +33472437286

Fax: +33472438531

\begin{abstract}
:
Selective laser ablation of dielectric layers on crystalline silicon wafers was investigated for solar cell fabrication. Laser processing was performed on $\mathrm{Al}_{2} \mathrm{O}_{3}$, and bi-layers $\mathrm{Al}_{2} \mathrm{O}_{3} / \mathrm{SiN}_{\mathrm{X}}: \mathrm{H}$ with a nanosecond $\mathrm{UV}$ laser at various energy densities ranging from 0.4 to 2 $\mathrm{J} . \mathrm{cm}^{-2}$. Ablation threshold was correlated to the simulated temperature at the interface between the dielectric coatings and the silicon substrate. Laser-induced damage to the silicon substrate was evaluated by time-resolved photoluminescence. The minority carrier lifetime deduced from time-resolved photoluminescence was related to the depth of the heat affected zone in the substrate.
\end{abstract}

Keywords: laser processing, ablation of dielectrics, $\mathrm{Al}_{2} \mathrm{O}_{3}, \mathrm{SiN}_{\mathrm{x}}$, minority carrier lifetime, photoluminescence, silicon solar cells.

\section{Introduction}

Laser technologies are gaining considerable attention for photovoltaics since they open ways to new structures with improved conversion efficiency. As an example, the rear-side of high efficiency silicon solar cells often includes rear side passivation and local contacts produced by laser ablation of a dielectric stack. The challenge of laser ablation is to achieve complete removal of selected areas without causing detrimental damage to the surrounding material [1, 2]. It is therefore necessary to control the surface quality after laser processing as laserinduced damage can reduce drastically the minority carrier lifetime in the substrate. Photoluminescence (PL) is a contactless and non-destructive technique to evaluate the effective minority carrier lifetime in semiconductors. Quasi steady-state and imaging PL techniques have been applied successfully to the characterization of solar cell fabrication including laser ablation steps [3, 4]. It has also been shown that room temperature PL spectroscopy was a sensitive technique to evaluate qualitatively the laser-induced damage after ablation of SiNx on silicon [5]. Recently, we have demonstrated that time-resolved photoluminescence (TRPL) measured by time correlated single photon counting (TCSPC) was well suited to extract the minority carrier effective lifetime in silicon [6]. It is a room 
temperature technique whose spatial resolution is limited by the dimension of the laser beam. In this work, we use TRPL to investigate the laser-induced damage in $\mathrm{Al}_{2} \mathrm{O}_{3}$ and bilayers $\mathrm{Al}_{2} \mathrm{O}_{3} / \mathrm{SiN}_{\mathrm{X}}: \mathrm{H}$ used as passivating and/or anti-reflection coatings in silicon solar cells. The ablation of these dielectric layers is challenging because their absorption at the laser wavelength is much smaller than that of the underlying Si substrate. Although laser ablation of SiNx has been quite thoroughly studied for photovoltaics application for example in [1, 2, 7, 8], ablation of $\mathrm{Al}_{2} \mathrm{O}_{3}$ has been less studied [9-11] despite the fact that it has become a widely used dielectric for Si solar cells particularly in combination with $\mathrm{SiNx}$ for back surface passivation of p-type solar cells. In the present work, simulations were used to relate the experimental observations to the temperature evolution at the interface between the silicon substrate and the dielectric coatings. The effect of the ablation fluence on the effective carrier lifetime was measured by TRPL and related to the thickness of the heat-effected zone.

\section{Sample preparation and preliminary characterization}

Double polished high quality n-type FZ crystalline silicon wafers were used for the experiments. Wafers were $250 \mu \mathrm{m}$-thick with a resistivity around $10 \Omega . \mathrm{cm}$. $\mathrm{Al}_{2} \mathrm{O}_{3}$ layers $(15$ $\mathrm{nm}$ thick) were deposited by thermal Atomic Layer Deposition (ALD). SiN $\mathrm{S}: \mathrm{H}$ layers (80 nm thick, refractive index around 2.01 at $635 \mathrm{~nm}$ ) were deposited by PECVD on $\mathrm{Al}_{2} \mathrm{O}_{3}$ substrates. Layer thicknesses were close to the values commonly used for passivating anti-reflection coating in silicon solar cells.

The ablation was achieved using a frequency tripled Nd:YAG laser (Rofin RSM 20E THG) with a Gaussian profile, a wavelength of $355 \mathrm{~nm}$ and a pulse duration of $10 \mathrm{~ns}$ [12]. The penetration depth of the UV laser in silicon was around $10 \mathrm{~nm}$. The laser spot diameter at the sample surface was around $25 \mu \mathrm{m}$. The scanning speed of the laser beam was chosen to have no overlap between the spots. Small areas $(6 \mathrm{~mm} \times 6 \mathrm{~mm})$ were ablated at different laser

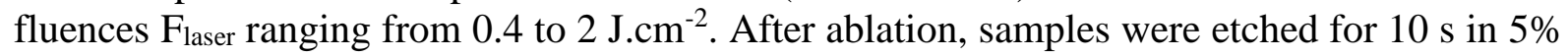
water diluted $\mathrm{HF}$ to remove the dielectric coatings that were locally ablated. Substrates were finally passivated on both sides by a $15 \mathrm{~nm}$-thick $\mathrm{Al}_{2} \mathrm{O}_{3}$ and annealed at $400^{\circ} \mathrm{C}$ for $10 \mathrm{~min}$ before minority carrier lifetime measurements.

Optical microscopy was used as a simple means to assess the ablation threshold and the surface quality. Ablation threshold of $\mathrm{Al}_{2} \mathrm{O}_{3}$ and $\mathrm{Al}_{2} \mathrm{O}_{3} / \mathrm{SiN}_{X}$ was observed around 0.85 and $0.95{\mathrm{~J} . \mathrm{cm}^{-2}}^{-}$respectively. Optical microscope observations after ablation of a $15 \mathrm{~nm}$ layer of $\mathrm{Al}_{2} \mathrm{O}_{3}$ on silicon are shown in Fig. 1 for two laser energy densities 1 and $2{\mathrm{~J} . \mathrm{cm}^{-2}}^{-}$. Partial removal of dielectrics at these fluences was attributed to the lack of pulse-to-pulse repeatability of the laser that is very critical close to the ablation threshold. Damage at the surface is attributed to the ablation of silicon that occurs around $1 \mathrm{~J} . \mathrm{cm}^{2}$. Severe damages with ablation of the silicon surface were observed at $2 \mathrm{~J} . \mathrm{cm}^{2}$ for both stacks.
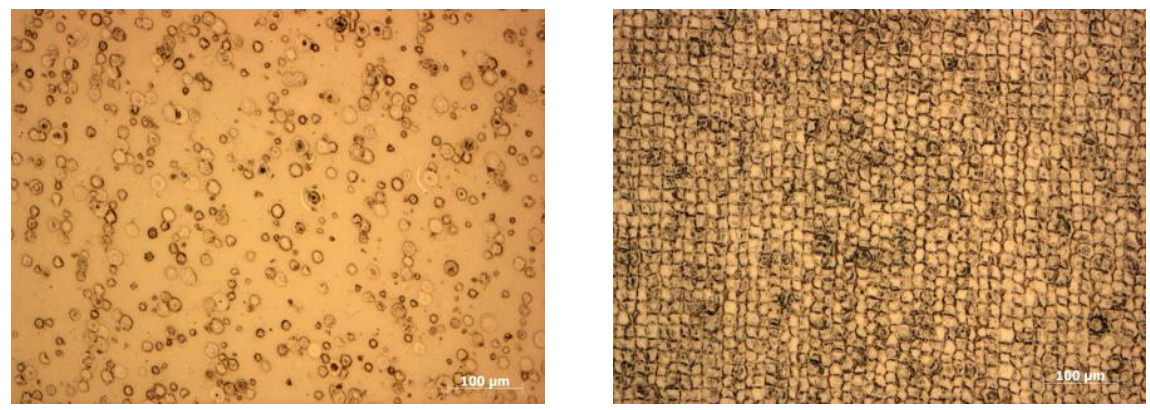
Fig. 1. Optical microscopy of a $\mathrm{Si} / \mathrm{Al}_{2} \mathrm{O}_{3}$ sample irradiated with a $355 \mathrm{~nm}$ nanosecond laser at fluences $1 \mathrm{~J} . \mathrm{cm}^{-2}$ (left) and $2 \mathrm{~J} . \mathrm{cm}^{-2}$ (right).

\section{Ablation mechanism}

Laser ablation of dielectrics has been shown to result from the vaporization of the material due to heat $[7,12]$. The thermal expansion of the underlying substrate and its vaporization has also been used to explain $\mathrm{SiO}_{2}$ and $\mathrm{SiN}_{\mathrm{x}}$ ablation on a $\mathrm{Si}$ substrate [2]. If the material has a small absorption coefficient at the laser wavelength, as it is the case for $\mathrm{Al}_{2} \mathrm{O}_{3}$ and stoichiometric $\mathrm{SiNx}$ in the UV range, ablation can still take place due to absorption in the highly absorbing silicon substrate. Due to the low absorption coefficient of $\mathrm{Al}_{2} \mathrm{O}_{3}$ and $\mathrm{SiN}_{\mathrm{x}}$ at $355 \mathrm{~nm}\left(\alpha_{\mathrm{Al} 2 \mathrm{O} 3} \sim 0\right.$ and $\left.\alpha_{\mathrm{SiNx}} \sim 3.5 \times 10^{2} \mathrm{~cm}^{-1}\right)$ compared to $\mathrm{Si}\left(\alpha_{\mathrm{Si}} \sim 10^{6} \mathrm{~cm}^{-1}\right)$ the laser absorption in the dielectric layers under study is negligible. Consequently the Si substrate behaves as a heat source after having absorbed the laser energy. The heat absorbed in Si is transferred by conduction in a few nanoseconds to the adjacent layers. While other complex mechanisms may occur during laser-matter interaction, ablation of the dielectric coatings under study can be explained by a vaporization mechanism when the temperature reached in the layer is of the order of the boiling temperature (respectively around $3253 \mathrm{~K}$ for $\mathrm{Al}_{2} \mathrm{O}_{3}$ and $2150 \mathrm{~K}$ for $\mathrm{SiN}_{\mathrm{x}}$ ).

\begin{tabular}{|l|l|l|l|}
\hline & $\begin{array}{l}\mathrm{Al}_{2} \mathrm{O}_{3} \\
\text { (crystalline) }\end{array}$ & $\mathrm{Si}_{3} \mathrm{~N}_{4}$ & $\begin{array}{l}\mathrm{Si} \\
\text { (crystalline) }\end{array}$ \\
\hline Melting point / sublimation temperature $(\mathrm{K})$ & 2343 & 2150 & 1683 \\
\hline Boiling point / vaporization temperature $(\mathrm{K})$ & 3253 & N.A. & 2628 \\
\hline Thermal conductivity solid state $\left(\mathrm{W} \mathrm{m}^{-1} \mathrm{~K}^{-1}\right)$ & 18 & 25 & 150 \\
\hline Thermal conductivity liquid state $\left(\mathrm{W} \mathrm{m}^{-1} \mathrm{~K}^{-1}\right)$ & $1-5.5$ & N.A. & $200-370$ \\
\hline
\end{tabular}

Tab. 1: Thermal properties of the materials under study [11].

Modelling of a single laser pulse interaction with the dielectric coatings on a Si substrate was done using the commercial software COMSOL Multiphysics [12]. The heat-transfer equation was solved for the two structures $\mathrm{Si} / \mathrm{Al}_{2} \mathrm{O}_{3}$ and $\mathrm{Si} / \mathrm{Al}_{2} \mathrm{O}_{3} / \mathrm{SiNx}$. Simulated thicknesses of the $\mathrm{Al}_{2} \mathrm{O}_{3}$ and $\mathrm{SiNx}$ layers were $15 \mathrm{~nm}$ and $80 \mathrm{~nm}$ respectively. The main thermal properties of the dielectric layers and silicon used in the simulation are given in Tab.1. However, the thermal properties commonly available for $\mathrm{Al}_{2} \mathrm{O}_{3}$ are those of the bulk material that are expected to differ from those of thin films. The maximum fluence used in the simulation is 1 $\mathrm{J} . \mathrm{cm}^{-2}$ which corresponds to the ablation threshold of Si. Fig. 2 shows an example of the temperature versus time at the $\mathrm{Si}$ surface of a stack $\mathrm{Si} / \mathrm{Al}_{2} \mathrm{O}_{3} / \mathrm{SiNx}$ submitted to a single pulse of fluence of $0.5 \mathrm{~J} . \mathrm{cm}^{-2}$.

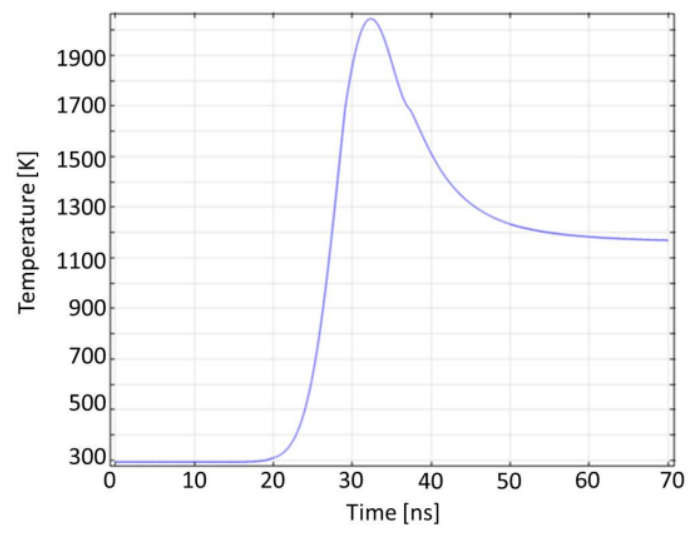


Fig. 2. Comsol simulation of the time evolution of the temperature at the $\mathrm{Si} / \mathrm{Al}_{2} \mathrm{O}_{3} / \mathrm{SiN}_{\mathrm{x}}$ interface for a laser fluence of $0.5 \mathrm{~J} . \mathrm{cm}^{-2}$.

In a similar way, the maximum temperature at the $\mathrm{Si}$ surface was computed for the different stacks and different laser fluences. Results are reported on Fig.3. The relevant melting and boiling temperatures of the materials under study are identified on the same graph. Melting of crystalline silicon takes place around $1680 \mathrm{~K}$. Decomposition of $\mathrm{SiN}_{\mathrm{x}}$ occurs at a temperature around $2150 \mathrm{~K}$ at which point the partial pressure of the $\mathrm{N}_{2}$ in the $\mathrm{SiN}_{\mathrm{x}}$ reaches one atmosphere and leads to the dielectric decomposition [3]. Dissociation of $\mathrm{Al}_{2} \mathrm{O}_{3}$ is expected to occur around $3250 \mathrm{~K}$.

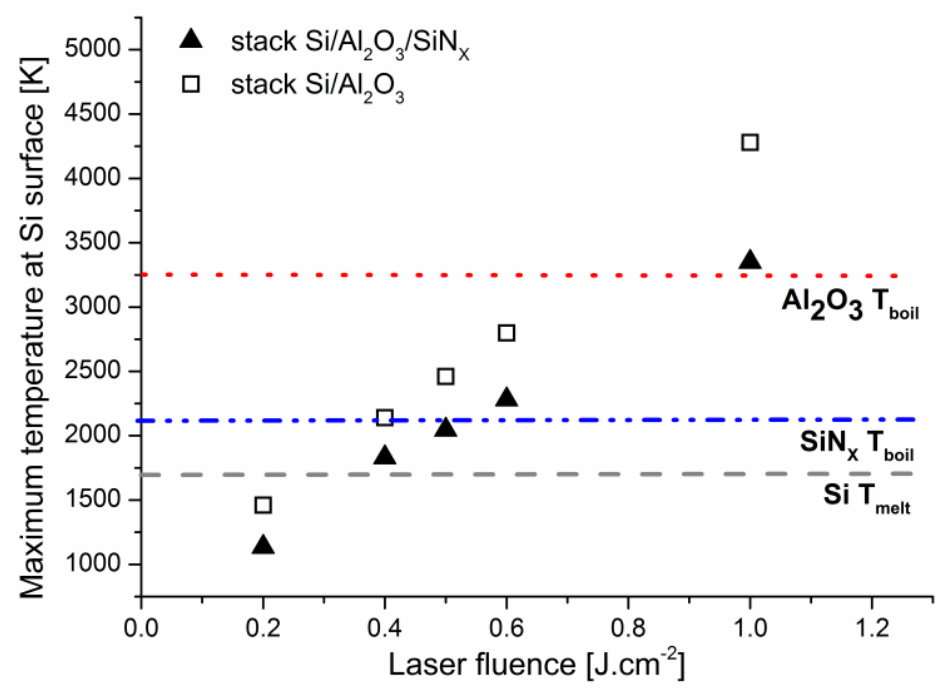

Fig.3. Comsol simulation of the maximum temperature at the interface dielectric/Si for different laser fluences (right).

The simulations show that $\mathrm{Al}_{2} \mathrm{O}_{3}$ removal is expected to start at an incident laser fluence around $0.7 \mathrm{~J} . \mathrm{cm}^{-2}$. This value is lower than the optical microscope observation. This may be due to the partial knowledge of the thermal properties of the dielectrics. For a given laser fluence, the simulated temperature at the $\mathrm{Si}$ surface is lower for $\mathrm{Si} / \mathrm{Al}_{2} \mathrm{O}_{3} / \mathrm{SiN}_{\mathrm{x}}$ than for $\mathrm{Si} / \mathrm{Al}_{2} \mathrm{O}_{3}$, probably due to the differences in the thermal conductivities. From around $0.4 \mathrm{~J} . \mathrm{cm}^{-}$ ${ }^{2}$ upwards, although the dielectric layers are not necessarily ablated, the interface Si/dielectric is thermally affected. Indeed, melting of the silicon surface causes a deterioration of the $\mathrm{Si}$ /dielectric interface due to the thermal expansion of the silicon in its liquid phase, corresponding to the observed thermally affected zone [12].

\section{Evaluation of the laser-induced damage by time-resolved photoluminescence}

Laser irradiation is expected to affect the $\mathrm{Si}$ substrate underneath the dielectric layer, even when low fluences are used. One way to evaluate the laser-induced damage in semiconductor is to measure the minority carrier lifetime. Minority carrier lifetime can be measured by timeresolved photoluminescence (TRPL) that records the time evolution of the excess carrier concentration generated by a pulsed optical excitation. A time-correlated single photon 
counting system (TCSPC) was developed for the measurement of TRPL in silicon at room temperature [6].

The excitation signal was provided by two laser diodes emitting at $870 \mathrm{~nm}$ or $405 \mathrm{~nm}$ over an area of $\sim 2 \mathrm{~mm}^{2}$. The penetration depth of the laser diodes in silicon was around $25 \mu \mathrm{m}$ and $0.1 \mu \mathrm{m}$ respectively and the power used was $50 \mathrm{~mW}$ and $120 \mathrm{~mW}$ respectively to ensure equivalent injection level in the silicon substrate. The laser diode intensity was modulated by a square-wave signal with a rise and fall time less than $1.5 \mathrm{~ns}$. The PL signal was directed through a monochromator to select the spectral range (10 nm wide) corresponding to the TO phonon assisted band-to-band recombination maximum in silicon around $1140 \mathrm{~nm}$. The PL signal was collected with an optical fiber plugged into a compact single photon counting system equipped with an InGaAs-based single photon avalanche diode (SPD_A_M1 from Aurea Technology). The electronics was designed to measure signal with characteristic decay time in the range of $1 \mu \mathrm{s}$ to $10 \mathrm{~ms}$. The photon counting system was synchronized with the modulated laser excitation via a time-correlation acquisition software package. The experimental set-up is represented in Fig.4.

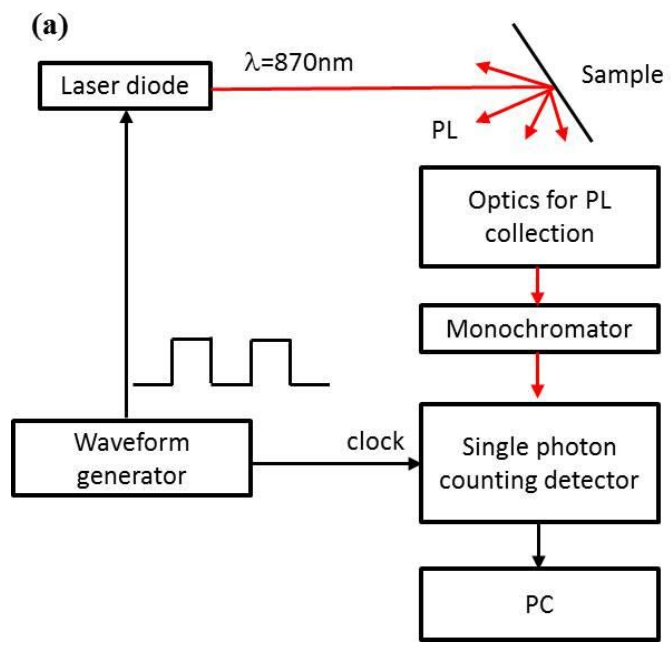

(b)

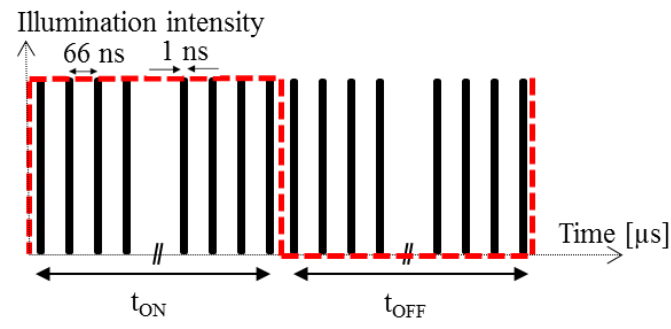

Fig. 4. (a) Schematic of the time-resolved photoluminescence measurement. (b) Principle of the single photon counting system. The dashed red line illustrates the periodic square-wave modulation signal. The thick black lines represent the time intervals at which the detector gate is opened (during $1 \mathrm{~ns}$ every $66 \mathrm{~ns}$ ).

Fig.5 gives an example of TRPL signals measured on an $\mathrm{Al}_{2} \mathrm{O}_{3}$-coated substrate that has been ablated with different laser fluences and passivated on both surfaces by $\mathrm{Al}_{2} \mathrm{O}_{3}$ before characterization. TRPL measurements were performed at $120 \mathrm{~mW}$ with the $405 \mathrm{~nm}$ laser diode. When the sample is illuminated the PL signal increases until a saturation level is reached which corresponds to the steady state condition. When the light is switched off, the PL intensity decreases according to a two exponential decay law. The steady-state signal provides a qualitative evaluation of the minority carrier lifetime, while the transient signal can be used to evaluate quantitatively to this parameter. 


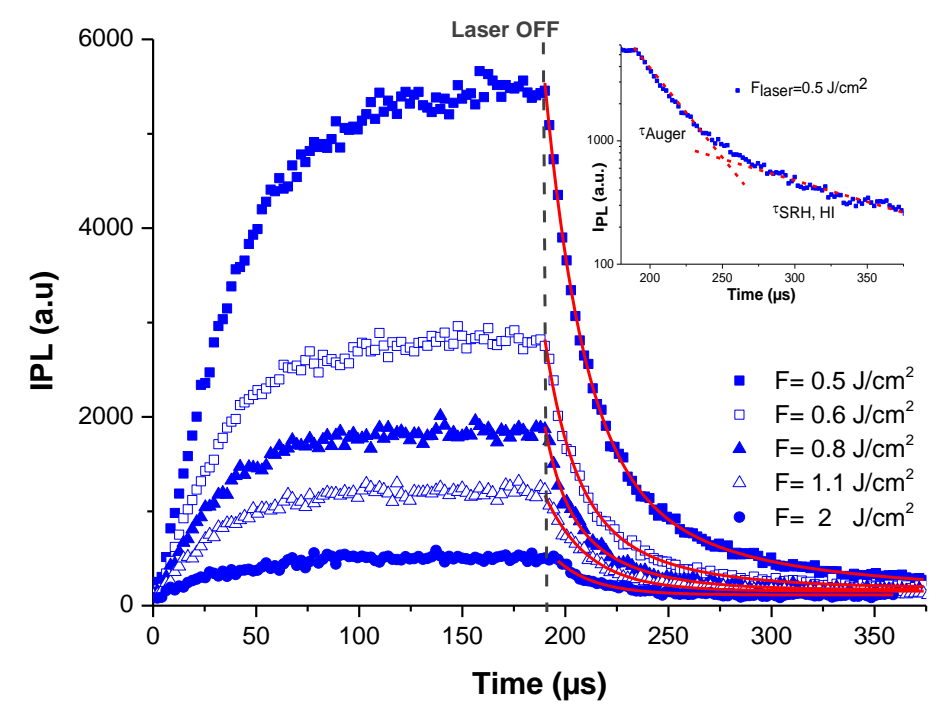

Fig. 5: PL intensity measured on an $\mathrm{Al}_{2} \mathrm{O}_{3}$-coated Si substrate after ablation at different laser fluences F. TRPL measurements were performed at $120 \mathrm{~mW}$ with laser diode emitting at 405 $\mathrm{nm}$. The exponential fits of the PL decays are shown in red and discussed in the text. The insert shows a semi-log plot of IPL versus time.

As expected the steady state PL signal decreases when the laser fluence increases due to thermal damage of the Si substrate. PL results measured with the $870 \mathrm{~nm}$ excitation diode showed a similar trend but the steady state signal intensity is less affected at high fluence values (above $0.8 \mathrm{~J}_{\mathrm{cm}} \mathrm{cm}^{-2}$ ). The maximum PL intensity measured on non-ablated samples was around 5 times larger than that measured after laser irradiation at $0.5 \mathrm{~J} . \mathrm{cm}^{-2}$. PL measurements were repeated for the two stacks $\mathrm{Si} / \mathrm{Al}_{2} \mathrm{O}_{3}$ and $\mathrm{Si} / \mathrm{Al}_{2} \mathrm{O}_{3} / \mathrm{SiN}_{\mathrm{x}}$ with the two available excitation wavelengths. The laser-induced damage (i.e. reduced PL signal) was consistently larger when measured with the blue laser $(405 \mathrm{~nm})$ that probes more efficiently the surface of silicon and the effect increases with the laser fluence. Considering the small penetration depth in silicon of the UV laser used for ablation (around $10 \mathrm{~nm}$ ), it is expected that the decrease of the PL is due to laser-induced defects located close to the surface that reduce the minority carrier lifetime.

Quantitative evaluation of the minority carrier lifetime could be obtained from the TRPL experiment. The PL intensity is given by the product of the free carrier densities in both the conduction and the valence bands. For a n-type Si substrate with a doping concentration $\mathrm{N}_{\mathrm{d}}$, the PL intensity IPL can be expressed as [6]:

$$
\mathrm{IPL} \sim \int_{0}^{W}\left[\Delta p(x) \cdot N_{d}+\Delta p(x)^{2}\right] \cdot d x
$$

Where $\Delta \mathrm{p}$ is the excess hole concentration. The simplified continuity equation gives the temporal behavior of $\Delta \mathrm{p}(\mathrm{t})$ when the excitation is switched off [13]:

$\mathrm{d}(\Delta \mathrm{p}(\mathrm{t})) / \mathrm{dt}=-\Delta \mathrm{p}(\mathrm{t}) / \tau_{\mathrm{eff}}$

$\tau_{\text {eff }}$ is the effective lifetime which depends on the excess carrier density, the bulk lifetime and 
the surface recombination lifetime. If $\tau_{\text {eff }}$ is considered as constant over the experimental data range (one order of magnitude in excess carrier density), the solution of Eq (2) can be expressed as:

$\Delta \mathrm{p}(\mathrm{t}) \sim \Delta \mathrm{p}_{0} \exp \left(-\mathrm{t} / \tau_{\mathrm{eff}}\right)$

Eq. 3

At high injection $\left(\Delta \mathrm{p}>>\mathrm{N}_{\mathrm{d}}\right)$ which corresponds to our experimental conditions $\left(\Delta \mathrm{p} \sim 5.10^{16}\right.$ $\mathrm{cm}^{-3}$ and $\mathrm{N}_{\mathrm{d}} \sim 5.10^{14} \mathrm{~cm}^{-3}$ ), the second term of Eq. (1) is predominant. In this case, IPL is proportional to the square of the excess hole concentration $\Delta \mathrm{p}(\mathrm{t})^{2}$ and varies as $\exp \left(-2 \mathrm{t} / \tau_{\text {eff }}\right)$. For very low surface recombination, as it is the case for the $\mathrm{Al}_{2} \mathrm{O}_{3}$ passivated Si substrate, the surface recombination velocity can be neglected and $\tau_{\text {eff }}$ represents the bulk lifetime. As shown in the insert of Fig.5, the PL decay can be fitted by a two exponential decay law.

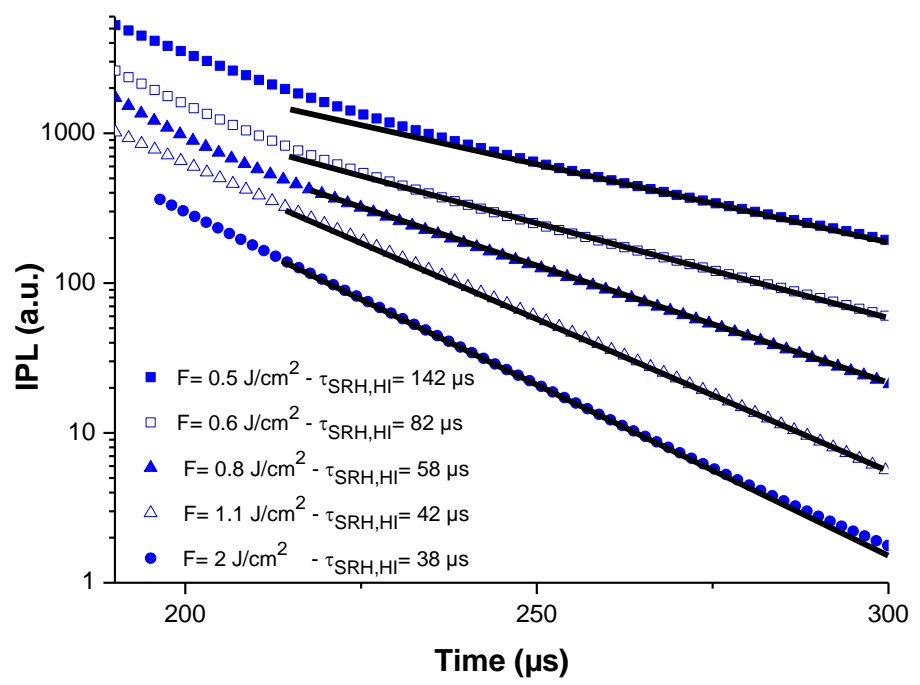

Fig. 6: Semi-log plot of the PL decay (from Fig. 5) measured on an $\mathrm{Al}_{2} \mathrm{O}_{3}$-coated Si substrate after ablation at different fluences F. TRPL measurements were performed at $120 \mathrm{~mW}$ with laser diode emitting at $405 \mathrm{~nm}$. The black lines corresponds to the SRH component of the minority carrier lifetime.

The first part of the decay (higher injection level) is attributed to the intrinsic Auger recombination while the second part is related to Shockley-Read-Hall recombination (SRH) at high injection. The characteristic time of the second part of the PL decay ( $\left.\tau_{\mathrm{SRH}, \mathrm{HI}}\right)$ is directly related to the level of defects in the bulk. Values of $\tau_{\mathrm{SRH}, \mathrm{HI}}$ measured (using Eq.3) on an $\mathrm{Al}_{2} \mathrm{O}_{3}$-coated $\mathrm{Si}$ substrate after ablation at different fluences $\left(0.5\right.$ to $2{\mathrm{~J} . \mathrm{cm}^{-3}}^{-3})$ are extracted from the semi-log plot of the PL decay as shown on Fig. 6. Although $\tau_{\mathrm{SRH}, \mathrm{HI}}$ decreases significantly from $142 \mu \mathrm{s}$ to $42 \mu \mathrm{s}$ between 0.5 to $1 \mathrm{~J} . \mathrm{cm}^{-3}$, it seems to level off after this value. In a similar way, Fig. 7 compares the TRPL decays measured at $870 \mathrm{~nm}$ and $405 \mathrm{~nm}$ on a $\mathrm{Si} / \mathrm{Al}_{2} \mathrm{O}_{3} / \mathrm{SiN}_{\mathrm{x}}$ stack irradiated at fluences below $\left(0.5 \mathrm{~J} . \mathrm{cm}^{-3}\right)$ and above $\left(1 \mathrm{~J} . \mathrm{cm}^{-3}\right)$ the ablation threshold. 


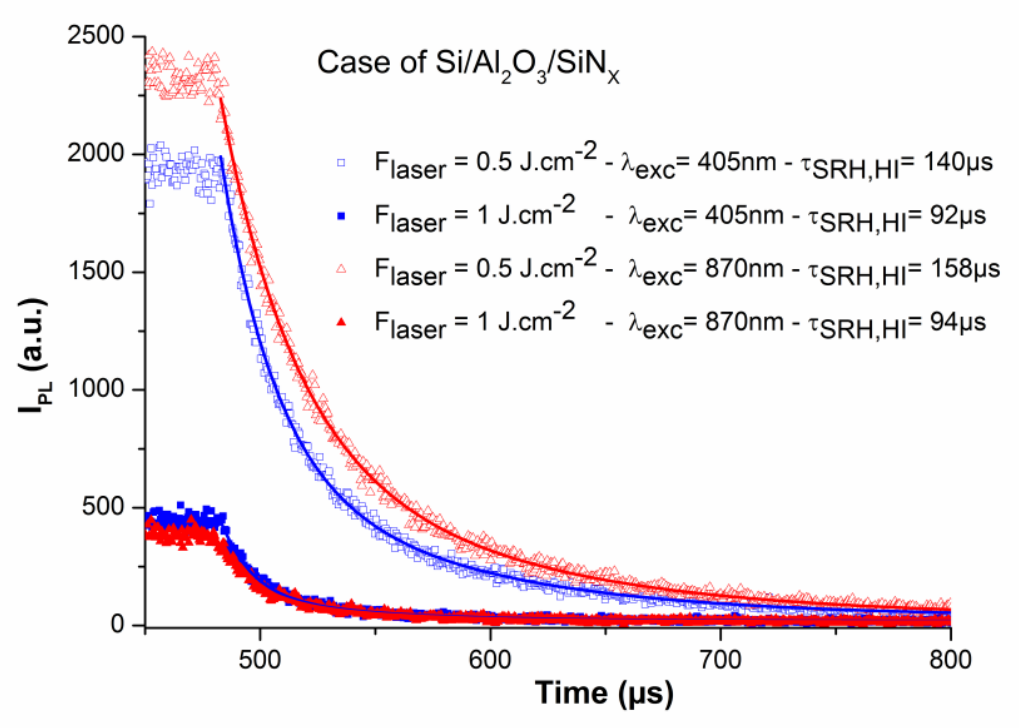

Fig. 7: TRPL decays measured at $870 \mathrm{~nm}$ and $405 \mathrm{~nm}$ on a $\mathrm{Si} / \mathrm{Al}_{2} \mathrm{O}_{3} / \mathrm{SiN}_{\mathrm{x}}$ stack irradiated at

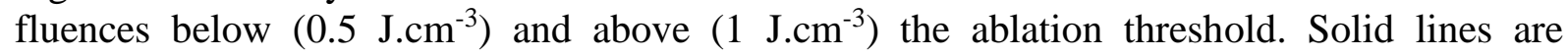
exponential fits of the data.

The lifetimes measured by TRPL are summarized in Tab. 2. Below the ablation threshold (laser fluence $0.5{\mathrm{~J} . \mathrm{cm}^{-3}}^{-}$) $\tau_{\mathrm{SRH}, \mathrm{HI}}$ is comparable (between $122 \mu \mathrm{s}$ and $158 \mu \mathrm{s}$ ) for the two samples at the two PL excitation wavelengths. When measured with the $405 \mathrm{~nm}$ laser, the damage induced at $1 \mathrm{~J} . \mathrm{cm}^{-3}$ is more pronounced in $\mathrm{Si} / \mathrm{Al}_{2} \mathrm{O}_{3}\left(\tau_{\mathrm{SRH}, \mathrm{HI}}=36 \mu \mathrm{s}\right)$ than in $\mathrm{Si} / \mathrm{Al}_{2} \mathrm{O}_{3} / \mathrm{SiN}_{\mathrm{x}}\left(\tau_{\mathrm{SRH}, \mathrm{HI}}=94 \mu \mathrm{s}\right)$ as expected from the Comsol simulation in Fig.3 as the temperature reached at the $\mathrm{Si}$ surface is less in the $\mathrm{Si} / \mathrm{Al}_{2} \mathrm{O}_{3} / \mathrm{SiN}_{\mathrm{x}}$ stack than in $\mathrm{Si} / \mathrm{Al}_{2} \mathrm{O}_{3}$. When measured with $870 \mathrm{~nm}$ laser that probes deeper in silicon, the damage induced at 1 $\mathrm{J} . \mathrm{cm}^{-3}$ is equivalent in the two samples $\left(\tau_{\mathrm{SRH}, \mathrm{HI}}=92 \mu \mathrm{s}\right)$. For comparison, spatially resolved minority carrier lifetime mapping was performed by microwave photo-conductance decay (Semilab WC-2000 $\mu \mathrm{W}$-PCD) on the same ablated areas. The equipment is using a laser source emitting at $904 \mathrm{~nm}$ and the injection level is comparable to that of the TRPL experiment. The TRPL lifetime values measured with the $870 \mathrm{~nm}$ laser are in good agreement with the $\mu \mathrm{W}$-PCD measurements for the $\mathrm{Si} / \mathrm{Al}_{2} \mathrm{O}_{3}$ sample but not so good for the $\mathrm{Si} / \mathrm{Al}_{2} \mathrm{O}_{3} / \mathrm{SiN}_{\mathrm{X}}$ stack, maybe due to some non-uniformities in the sample.

\begin{tabular}{|c|c|c|c|c|}
\hline Sample & $\begin{array}{c}\text { Laser Fluence } \\
\left(\mathrm{J} . \mathrm{cm}^{-2}\right)\end{array}$ & $\begin{array}{c}\tau_{\mathrm{SRH}, \mathrm{HI}}(\mu \mathrm{s}) \\
\text { TRPL@ 405 nm }\end{array}$ & $\begin{array}{c}\tau_{\mathrm{SRH}, \mathrm{HI}}(\mu \mathrm{s}) \\
\text { TRPL@ 870nm }\end{array}$ & $\begin{array}{c}\tau_{\text {eff }}(\mu \mathrm{s}) \\
\mu \mathrm{W}-\mathrm{PCD} @ 904 \mathrm{~nm}\end{array}$ \\
\hline $\mathrm{Si} / \mathrm{Al}_{2} \mathrm{O}_{3}$ & 0.5 & 136 & 122 & 140 \\
\hline $\mathrm{Si} / \mathrm{Al}_{2} \mathrm{O}_{3}$ & 1 & 36 & 92 & 95 \\
\hline $\mathrm{Si} / \mathrm{Al}_{2} \mathrm{O}_{3} / \mathrm{SiN}_{\mathrm{x}}$ & 0.5 & 140 & 158 & 336 \\
\hline $\mathrm{Si} / \mathrm{Al}_{2} \mathrm{O}_{3} / \mathrm{SiN}_{\mathrm{x}}$ & 1 & 94 & 92 & 144 \\
\hline
\end{tabular}

Tab. 2: Minority carrier lifetime measured by TRPL and $\mu \mathrm{W}-\mathrm{PCD}$ (Semilab).

Finally, simulations of the photoluminescence intensity were carried out to link the minority carrier lifetime to the laser-induced damage in the substrate. The time-dependent simulated photoluminescence signal was generated with PC1D software (One-Dimensional semiconductor device simulator on Personal Computer [14]) where the excess minority carrier concentration under laser illumination can be calculated as a function of time at a specified 
depth in the sample [6]. The effect of the laser-induced damage was simulated by introducing a heat-affected zone (HAZ) with a variable thickness and a low bulk lifetime $(0.1 \mu \mathrm{s})$ at the surface of the $250 \mu \mathrm{m} \mathrm{Si}$ substrate with a high bulk lifetime $(1 \mathrm{~ms})$. The surface recombination velocity on both surfaces passivated with $\mathrm{Al}_{2} \mathrm{O}_{3}$ was kept constant and equal to $20 \mathrm{~cm} / \mathrm{s}$. The theoretical $\Delta \mathrm{p}(\mathrm{t})$ signal was fitted with Eq. 3 and the $\tau_{\text {eff }}$ value was compared to the experiment. When the width of the HAZ is varied in proportion to the change in fluence (for a suitable starting value at the lowest fluence), the bulk minority carrier lifetime is found to follow the same trend as the experimental values, as shown in Fig. 8. During ablation of $\mathrm{Al}_{2} \mathrm{O}_{3}$ at $0.5 \mathrm{~J} . \mathrm{cm}^{-3}$, the HAZ extends to roughly to $0.75 \mu \mathrm{m}$ below the $\mathrm{Si}$ surface, while it becomes $1.5 \mu \mathrm{m}$ for a laser fluence of $1 \mathrm{~J} . \mathrm{cm}^{-3}$.

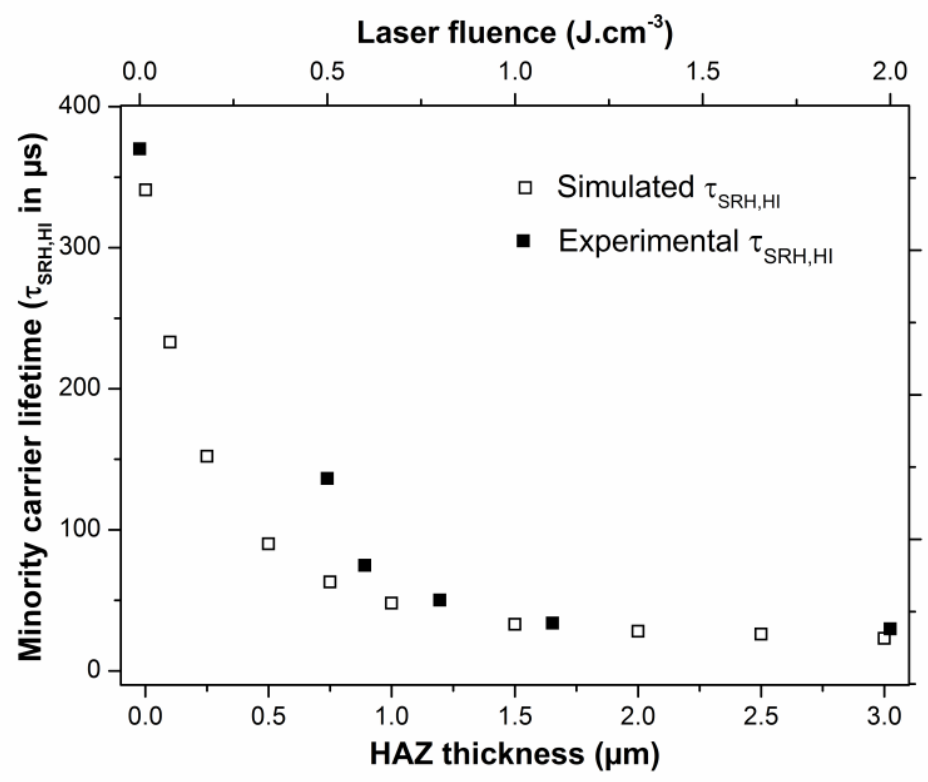

Fig. 8: Measured minority carrier lifetime $\mathrm{Si} / \mathrm{Al}_{2} \mathrm{O}_{3}$ stack versus the ablation laser fluence and simulated minority carrier lifetime as a function of the heat affected zone thickness.

Overall the characterization and modelling results show that the decrease of the average minority carrier lifetime and photoluminescence efficiency with laser fluence can be attributed to an increase in the concentration of defects near the surface. HAZ thicknesses can be compared to the value of thermal diffusion length associated with the laser pulse used for ablation $\left(\delta_{\text {th }}=2\left(\tau \kappa_{\text {th }} / \rho \mathrm{C}_{\mathrm{p}}\right)^{1 / 2}\right.$ where $\tau$ is the pulse duration of the laser and $\kappa_{\text {th }}, \rho$ and $C_{p}$ are respectively the thermal conductivity, the mass per unit volume and the specific heat of silicon [15]. For silicon $\delta_{\text {th }}$ is around $1.8 \mu \mathrm{m}$ for a pulse duration of $10 \mathrm{~ns}$. This value is in good agreement with the range of HAZ thicknesses estimated from PC1D simulation.

\section{Conclusion}

Ablation of dielectrics $\mathrm{Al}_{2} \mathrm{O}_{3}$ and $\mathrm{Al}_{2} \mathrm{O}_{3} / \mathrm{SiNx}$ on $\mathrm{Si}$ substrates was performed with a nanosecond UV laser. The ablation thresholds were found in good agreement with COMSOL simulation, around 0.85 and $0.95 \mathrm{~J}_{\mathrm{cm}} \mathrm{cm}^{-2}$ for $\mathrm{Al}_{2} \mathrm{O}_{3}$ and $\mathrm{Al}_{2} \mathrm{O}_{3} / \mathrm{SiN}_{\mathrm{X}}$ respectively. These values

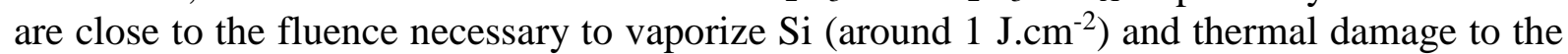
substrate are therefore expected. Laser-induced damage was evaluated at room temperature by TRPL with a single photon counting detector. Steady state and transient PL measurement were used to relate the laser fluence and the damage induced in the Si substrate. Steady state PL intensity decreases as expected when the laser fluence increases and is reduced when 
excited with a laser absorbed close to the surface. Minority carrier lifetime can be deduced from the PL decay and can be related to the thickness of the heat affected zone. Although minority carrier lifetime is affected by the laser induced heating, ablation of $\mathrm{Al}_{2} \mathrm{O}_{3} / \mathrm{SiNx}$ coatings on the rear side is possible as photo-induced damage is less critical at the rear side of the solar cell. Further studies are still necessary to identify the nature of the laser-induced defects that could be attributed to dislocations that appear at the interface between the melted zone and the bulk during cooling.

\section{Acknowledgements}

Corina Barbos is supported by a grant from Région Rhône-Alpes (ARC-4 Energies). The research leading to these results has received funding from OSEO for the project "MONOXEN". The authors would like to thank the PC1D team for developing a very useful and user-friendly free software.

\section{References}

[1] A. Knorz, M. Peters, A. Grohe, C. Harmel, R. Preu, Selective laser ablation of SiNx layers on textured surfaces for low temperature front side metallization, Prog. Photovolt: Res. Appl. 17 (2009) 127-136.

[2] S. Hermann, T. Dezhdar, N. P. Harder, R. Brendel, M. Seibt, S. Stroj, Impact of surface topography and laser pulse duration for laser ablation of solar cell front side passivating $\mathrm{SiN}_{\mathrm{x}}$ layers, J. Appl. Phys. 108 (2010) 114514-114521.

[3] T. Trupke, R.A. Bardos, M.C. Schubert, W. Warta, Photoluminescence imaging of silicon wafers Appl. Phys. Lett. 89 (2006) 044107-044109.

[4] M. D. Abbott, J. E. Cotter, F. W. Chen, T. Trupke, R. A. Bardos, and K. C. Fisher, Application of photoluminescence characterization to the development and manufacturing of high-efficiency silicon solar cells, J. Appl. Phys. 100 (2006) 114514-114523.

[5] G. Poulain, D. Blanc, A. Focsa, M. De Vita, K. Fraser, Y. Sayad, M. Lemiti, Characterization of laser-induced damage in silicon solar cells during selective ablation processes, Materials Science and Engineering B 178 (2013) 682- 685.

[6] S. Parola, M Daanoune, A Kaminski-Cachopo, M Lemiti, D Blanc-Pélissier, Timeresolved photoluminescence for self-calibrated injection-dependent minority carrier lifetime measurements in silicon J. Phys. D: Appl. Phys. 48 (2015) 035102-035108.

[7] S.A.G.D. Correia, J. Lossen, M. Wald, K. Neckermann, M. Bähr, Selective laser ablation of dielectric layers, in: Proceedings of $22^{\text {nd }}$ European Photovoltaic Solar Energy Conference, Milan, Italy (2007) 1061-1067.

[8] C. Geisler, S. Kluska, S. Hopman, M. Glatthaar, Passivation-Induced Cavity Defects in Laser-Doped Selective Emitter Si Solar Cells Formation Model and Recombination Analysis, IEEE Journal of Photovoltaics, 5 (2015) 792-798. 
[9] Y Jin, P Yoon, C Park, J Jang, J Kim, G Shim, Y Choe and J Jeong, Selective laser ablation of dielectrics on textured n-type wafers, 26th European Photovoltaic Solar Energy Conference and Exhibition, (2011) 507-511.

[10] P. Jaffrennou, A. Uruena, J. Das, J. Penaud, M. Moors, A. Rothschild, B. Lombardet, J. Szlufcik, Laser ablation of $\mathrm{SiO} 2 / \mathrm{SiNx}$ and $\mathrm{AlOx} / \mathrm{SiNx}$ back side passivation stacks for advanced cell architectures, 26th European Photovoltaic Solar Energy Conference and Exhibition, (2011) 1180-1183.

[11] T. Schutz-Kuchly, A. Slaoui, J. Zelgowski, A. Bahouka, M. Pawlik, J.P. Vilcot, E. Delbos, M. Bouttemy, R. Cabal, UV and IR laser induced ablation of Al2O3/SiN:H and aSi:H/SiN:H, EPJ Photovoltaics, 5 (2014) 55201-55205.

[12] G. Poulain, D. Blanc, A. Focsa, M. De Vita, B. Semmache, M. Gauthier, Y. Pellegrin, M. Lemiti, Laser ablation mechanism of silicon nitride layers in a nanosecond UV regime, Energy Procedia, 27 (2012) 516-521.

[13] H. Nagel, C. Berge, A. G. Aberle, Generalized analysis of quasi-steady state and quasitransient measurements of carrier lifetimes in semiconductors, J. Appl. Phys. 86 (1999) 62186221.

[14] D. A. Clugston, P. A. Basore, PC1D Version 5: 32-Bit solar cell modeling on personal computers, $26^{\text {th }}$ IEEE Photovoltaic Specialists Conference (1997) 207-210.

[15] D. Bäuerle, Laser Processing and Chemistry, $3^{\text {rd }}$ edition, Springer, 2011, pp.19-20. 